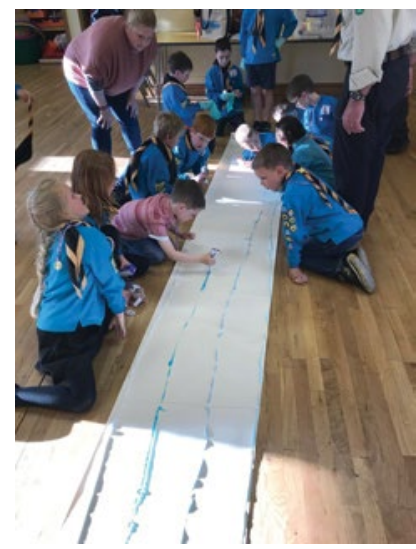

« all know what they have to do and for how long - two minutes - then it is time to start. All chew the tablet for 30 seconds then swish it around and look in the mirror. The noise level soon gets out of hand so arm up again! The big egg timer turns over and off we all go: brushing as demonstrated. After two minutes everyone can rinse out and then if you have the luxury of having a back-up, they then show the children the results and if they've done good then they get a medal ... and of course they've all 'done good'.

So far so good, but the evening hasn't finished yet and the children are keen to find out what is next on the agenda.

4) The research project is next. The task is to compare how much toothpaste is in various tubes (four) and various makes.

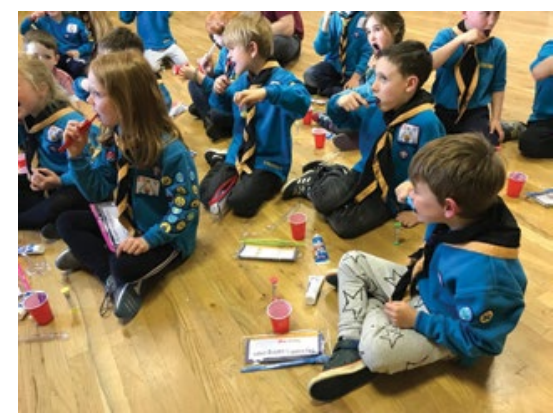

To do that a roll of wallpaper is spread out on the floor and the group is split into four teams. Each team member takes it in turn to squeeze out some toothpaste to end up with a continuous line. The line must be intact but the thinner it can be made the longer the line will be. This demands a huge amount of concentration and team effort and is taken very seriously. The results have been surprisingly consistent with the major brands all resulting in virtually the same measurement. The one brand that always comes out ahead by a long margin is a well-known sensitivity toothpaste. Why that is, is a mystery!

After the session is finished we need a summing up chat with questions on what has been learnt and whether anything will change or was it all known about before.

Your amazing assistant will have blown up balloons and attached them to the toothbrush pack with their name on for them to

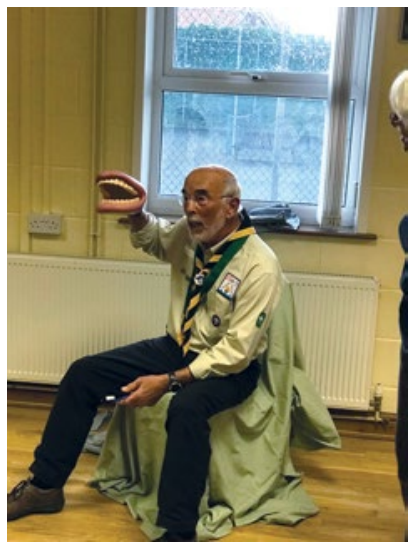

take home to show off what they've learnt to their long suffering parents.

Your fun evening has the potential to reach out to a large number of folk. With the 100 youngsters in my group that's nearly 200 parents, 300-400 grandparents and something like another 100 brothers and sisters, to say nothing of aunts and uncles etc. You will have planted some valuable seeds in young people's minds and that is amazingly worthwhile, so now you can go home and relish a decent dram or whatever is the tipple of choice because you also have 'done good'.

Thanks for advice and support to Heather Chapple BDS (St And), Jonathan Chapple BDS, MFDS RCS(Edin), MSc, MOrth RCS(Edin), FDS(Orth) RCS(Edin), Gemma Chapple MA and Carole Marlow EDH.

\title{
Oral health in the curriculum is 'fantastic news'
}

The Faculty of General Dental Practice (UK) has welcomed the inclusion of oral health in new statutory guidance on health education for schools in England. ${ }^{1}$

The UK was recently ranked the lowest of 13 countries for providing oral health education in schools, but the new guidance will require that both primary and secondary school pupils are taught about dental health, including the benefits of good oral hygiene, dental flossing and regular dental check-ups, the characteristics of a poor diet, and the risks associated with unhealthy eating, including tooth decay.

Health education is not currently mandatory in England, but will become a statutory duty when the guidance takes effect in September 2020, and schools are being encouraged to implement the new guidance in full from this year. Oral health is likely to

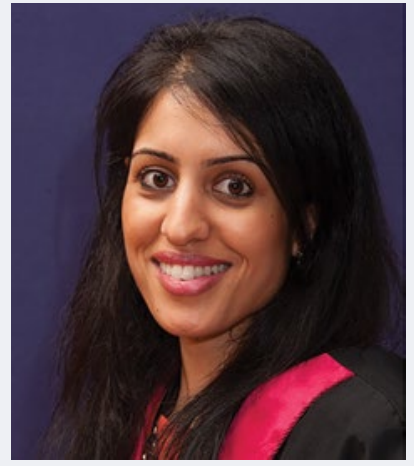

Roshni Karia

be taught as part of Personal, Social, Health and Economic (PHSE) lessons, which already take place in most state-funded schools in England.

Roshni Karia, Vice-Dean of FGDP(UK) and the Faculty's representative on Public Health England's Children's Oral Health Improvement Programme Board (pictured), said: 'Many children and parents are still unsure about what good oral health looks like, and are unaware of its importance for general health. As dentists we only get the chance to provide this message to those that come to see us, but unfortunately up to a third of school-aged children don't. So the inclusion of oral health in the school curriculum is fantastic news, and potentially a very significant moment in improving children's oral health'

\section{References}

1. Department for Education. Relationships education relationships and sex education (RSE) and Health Education. Statutory guidance for governing bodies, proprietors, head teachers, principals, senior leadership teams, teachers. 2019. Available at: https://assets.publishing.service.gov.uk/government/uploads/system/uploads/attachment_data/ file/805781/Relationships_Education__Relationships_and_Sex_Education__RSE__and_Health_ Education.pdf (accessed August 2019). 